\title{
Arrugas Bone Trephine Assisted Flapless Dacryocystorhinostomy with Circumosteal - Mitomycin C Versus External Dacryocystorhinostomy: A Hospital Based Comparative Study
}

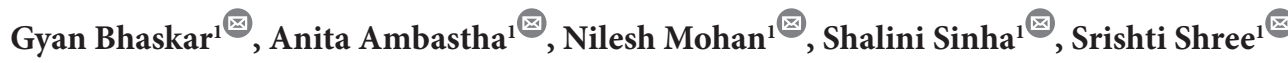 \\ ${ }^{1}$ Regional Institute of Ophthalmology, Indira Gandhi Institute of Medical Sciences, Patna, Bihar, India
}

\begin{abstract}
Introduction: Primary acquired nasolacrimal duct obstruction is a common ophthalmic condition and has conventionally been managed by external dacryocystorhinostomy. However this procedure is time consuming and involves making mucosal flaps. The aim of this study was to compare the surgical outcome in Arrugas bone trephine-assisted flapless dacryocystorhinostomy with Circumosteal - Mitomycin C versus conventional external dacryocystorhinostomy.
\end{abstract}

Materials and methods: This is a retrospective non-randomized study of surgical outcome in patients of primary acquired nasolacrimal duct obstruction who underwent an Arrugas bone trephine assisted flapless dacryocystorhinostomy with Circumosteal - Mitomycin C (group A) versus those who underwent conventional external dacryocystorhinostomy (group B) in a teaching hospital in North India. Patients with previously failed dacryocystorhinostomy, lacrimal fistula, canalicular and common canalicular obstruction were excluded. Success was defined as patent syringing at the end of one year. Surgical time was calculated from skin incision to skin suturing.

Results: There was complete resolution of epiphora with patent syringing in 43 out of 52 patients in group A, while in group B, 47 out of 55 patients had complete resolution of epiphora with patent syringing at the end of one year $(p=0.77)$. Mean surgical time was significantly lower in Group A than in Group B $(\mathrm{p}=<.05)$. Scarring and closure of the ostium was the most common cause of failure in both groups (Group A, $n=5,9.6 \%$; Group B, $n=3,5.45 \%)$.

Conclusion: Arrugas bone trephine-assisted flapless dacryocystorhinostomy with Circumosteal Mitomycin $\mathrm{C}$ is a viable alternative to conventional external dacryocystorhinostomy with comparable success rate and shorter surgical time and a faster learning curve.

Key words: Arrugas bone trephine, Circumosteal - Mitomycin C, External Dacryocystorhinostomy, Flapless DCR, Primary acquired nasolacrimal duct obstruction.

Financial Interest : Nil

Conflict of Interest : Nil

Received : 03.01.2021

Accepted : 06.06.2021

Corresponding Author

Dr. Anita Ambastha

Regional Institute of Ophthalmology,

Indira Gandhi Institute of Medical Sciences,

Patna, Bihar, India

E-mail: ambasthaanita@yahoo.in

Contact: +919304456082
Access this article online

Website: www.nepjol.info/index.php/NEPJOPH

DOI: https://doi.org/10.3126/nepjoph.v13i2.30264

Copyright $\odot 2021$ Nepal Ophthalmic Society ISSN: 2072-6805, E-ISSN: 2091-0320

This work is licensed under a Creative Commons Attribution-NonCommercial-NoDerivatives 4.0 International License (CC BY-NC-ND). 


\section{INTRODUCTION}

Dacryocystorhinostomy (DCR) is a common surgery done for the management of the epiphora due to primary acquired nasolacrimal duct obstruction (PANLDO). It was first described by Totis(1904).

DCR is done to eliminate the fluid and mucus retention in the lacrimal sac by establishing a low resistance drainage pathway between the tear sac and nasal cavity. The conventional procedure is successful and the reported success rate varies between $85 \%$ to $99 \%$ (Warren $F$ et al, 2005; Rabina G et al, 2013; Ali et al, 2014). However, a study noted a success rate of $58 \%$ in the inexperienced surgeons' group versus 94\% in the experienced group doing Ext DCR (Onerci M, 2000). Failure is attributed to many factors - common canalicular obstruction, scarring within anastomosis, closure of osteotomy site by membrane, adhesion or synechia formation between ostium and middle turbinate or a deviated nasal septum and malpositioned ostia (Mc LCJ et al, 1999; Tarbet KJ, 1995; Ezra E et al, 1998).

Anti-metabolites, like mitomycin-C (MMC) inhibit circumosteal scarring and ostium closure with its antifibrotic action. Studies have suggested the role of MMC per operatively and postoperatively in conventional Ext DCR in maintaining a patent ostium and thereby increasing its success rate (Iqbal A et al, 2012; Kamal et al, 2014). When used in conjunction with Arrugas bone trephine-assisted osteotomy, which ensures an adequate size of osteum with smooth margin, the chance of maintaining a patent might be more. Here we report a modification in the conventional technique where circumostial injection of mitomycin $\mathrm{C}$ (COS-MMC) was given in Arrugas bone trephine assisted flapless DCR and compared it with results of conventional Ext DCR.

\section{MATERIALS AND METHODS}

Aretrospective analysis of one hundred and seven patients with primary acquired nasolacrimal duct obstruction who had undergone sac surgery between May 2016 to October 2019, was done at our teaching hospital. Records of patients who had undergone sac surgery were analyzed. Examination of each eye with special emphasis on examination of the lacrimal system was done. Patients between 18 to 70 years with regurgitation on pressure over the lacrimal area (ROPLAS) or diagnostic lacrimal syringing and probing indicative of PANLDO were included in the study. Patients with coexistent lid laxity, lower lid ectropion or lid margin abnormalities were excluded. Those whose records showed secondary nasolacrimal duct or canalicular obstruction, lacrimal fistula, previously failed sac surgery or a bleeding pathology were also excluded from the study. All surgeries were performed by a single surgeon. Records of patients who had undergone Arrugas bone trephine assisted flapless DCR with COS MMC (Group A) or conventional Ext DCR (Group B) and who fulfilled the exclusion and inclusion criteria were compared and analysed. 
Surgical technique: Surgery was done under local anaesthesia after routine preoperative investigations and preparation for DCR Surgery. Anesthesia of the nasal mucosa consisted of 2 $\mathrm{ml}$ xylocaine 5\% with adrenaline 1:100,000. Initial steps in both the procedures were similar. A curvilinear skin incision of 10 to $15 \mathrm{~mm}$, corresponding to anterior lacrimal crest was made, care being taken to avoid trauma to the angular vein. Blunt dissection of the orbicularis and exposure of the lacrimal sac was done.

In Arrugas Bone trephine assisted Flapless DCR with COS-MMC technique (Group A), the sac was identified followed by its anterior and posterior part being excised, leaving a small collar around the common internal opening
(Figure 1a, 1b). The area around the common internal opening was handled carefully so as to not damage it. A bony osteum of $10 \mathrm{~mm}$ using Arrugas bone trephine (size $10 \mathrm{~mm}$ ) was made in the lateral nasal wall (Figure 1c). A corresponding part of nasal mucosa was then removed along with bone so that the internal common opening was facing the nasal cavity (Figure 1d, 1e). A circumosteal intramucosal injection of $0.02 \% \mathrm{MMC}(0.1 \mathrm{ml})$ was given along the margin of the ostium at four places each (Figure 1g, 1h). The anterior remaining small collar of the sac was sutured along with orbicularis muscle and the subcutaneous tissue with 6-0 vicryl (Ethicon Inc.). Skin was opposed using 6-0 mersilk.
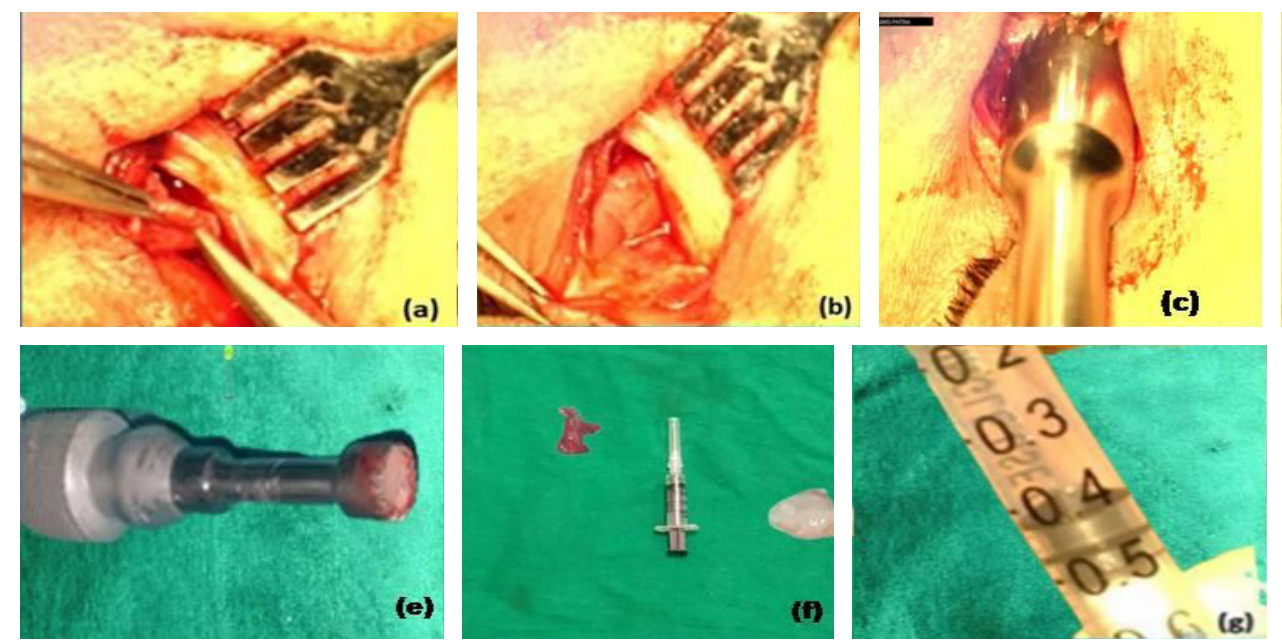
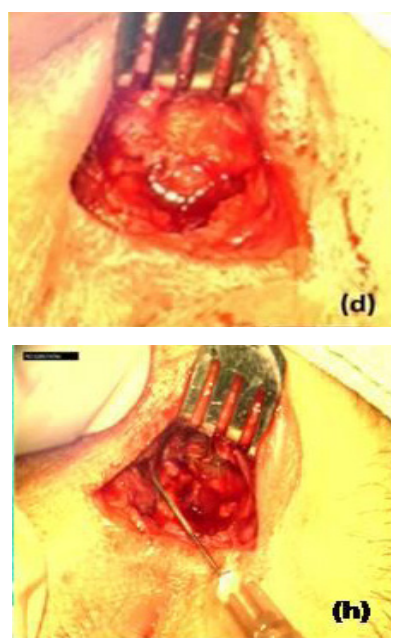

Figure 1: Surgical steps of DCR with circumosteal MMC (Group A); Figure 1a: Cutting of sac wall; Figure 1b: Internal common opening; Figure 1c: Making ostium; Figure 1d: Ostium; Figure 1e: Bone trephine; Figure 1f: Mucosa and sac; Figure 1g: MMC in syringe; Figure 1h: Intra osteal injection. 


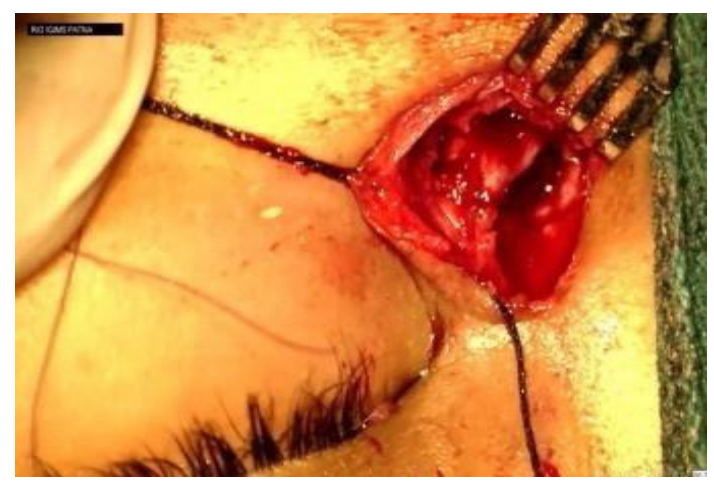

Figure 2: Conventional external DCR (Group B) - Anastomosis of the sac wall with nasal mucosa.

In Group B, after identifying the sac, H- shaped flaps were made. Posterior flap was excised. Bony osteum of appropriate size was made and nasal mucosa incised in an $\mathrm{H}$ pattern. Posterior flap was excised while the anterior flap was sutured with an anterior flap of sac mucosa (Figure 2) and wound closure was done.

Post operatively all patients were given oral and local antibiotics along with nasal decongestants for 1 week. The stitches were removed ten days post surgery. Follow ups were done on day one and seven and thereafter at the end of one month, three month, and one year respectively from the day of surgery. At each visit, irrigation with sterile saline was done and cases were examined for any complications such as wound gap, infection, discharge and epistaxis. Surgical success was defined by anatomical patency of the lacrimal drainage system on irrigation.
Institute ethical committee clearance was taken and the tenets of Helsinki were adhered to. Statistical analysis was performed using SPSS software. Significance was defined as $p<0.05$. Demographics and baseline characteristics were summarized using descriptive statistics. Categorical variables were summarized using frequencies and percentages. To compare the categorical variables between groups, the chisquare test was used to assess if differences exist.

\section{RESULTS}

Group A had 24 females and 28 males (mean age $51.50 \pm 16.6$ years ) (Range 18-70 years) while group B had 26 females and 29males respectively (mean age $53.45 \pm 17.7$ years) (Range 18-70 years).

Table 1: Demography.

\begin{tabular}{|l|c|c|c|}
\hline & Group A & Group B & p value \\
\hline M:F & $28: 24$ & $29: 26$ & $0.70^{*}$ \\
\hline RE: LE & $27: 23$ & $21: 29$ & $0.23^{*}$ \\
\hline MEAN AGE & $49 \pm 11$ & $52 \pm 13$ & $0.21^{* *}$ \\
\hline
\end{tabular}

*chi-square test; ${ }^{* *}$ Two-tailed $\mathrm{p}$ value using unpaired $\mathrm{t}$ test. 
Most common presenting complaint was mucopurulent discharge in both group A $(n=44,85 \%)$ and group B $(n=46,83 \%)$. Most common intraoperative complication in Group A was intraoperative bleeding. In group B, the most common intraoperative complication was bleeding followed by loss of nasal mucosa ( 8 cases) and failure of marsupialization of the sac (2 cases)(Table 2). Postoperatively, eight patients in Group A and five patients in Group B had nasal bleeding ( $\mathrm{p}=>$.05) (Table 3). Total surgical time in Group A was found to be significantly less than Group B $(\mathrm{p}<0.01)$ (Table 4). The bleeding was not considered abnormal and resolved on repacking the nasal mucosa. There was complete resolution of epiphora with patent syringing in 43 patients of group $A$, while in group B, 47 patients had complete resolution of epiphora with patent syringing at the end of one year $(\mathrm{p}=>0.05)$. Patients with failed patency test on syringing underwent re-surgery. Seven cases of failure in Group A were found to be due to cicatricial closure of the ostium. In one case granuloma was found blocking the ostium. In Group B, five patients were found to have blocked ostium while an intact sac was found in one case. Apparently, the lacrimal fascia in place of the sac had been dissected and anastomosed with the nasal mucosa. One case in group B had patent syringing but persistent watering which was attributed to post-op complication of ectropion which was later managed surgically . No adverse effects like abnormal nasal bleeding, mucosal necrosis, infection or any other adverse surgical events were observed in any group.

\section{DISCUSSION}

Table 2: Comparison of intraoperative complications between groups $A$ and $B$.

\begin{tabular}{|l|c|c|c|}
\hline \multicolumn{1}{|c|}{ Intraoperative complication } & Group A & Group B & p value \\
\hline Intraoperative bleeding needing a fresh nasal pack & 12 & 8 & $>.01$ \\
\hline Intraoperative loss of sac mucosa & NA & 1 & $>.01$ \\
\hline Intraoperative loss of nasal mucosa & NA & 6 & $>.01$ \\
\hline
\end{tabular}

Table 3: Comparison of postoperative complications between groups A and B.

\begin{tabular}{|l|c|c|c|}
\hline \multicolumn{1}{|c|}{ Post-operative complications } & Group A & Group B & p value \\
\hline Lid and incisional edema & 7 & 6 & $>.01$ \\
\hline Post-operative nasal bleed & 6 & 3 & $>.01$ \\
\hline Failed NLD patency test & 6 & 4 & $0.74^{*}$ \\
\hline
\end{tabular}

*Two-tailed $p$ value is less than Fisher's exact test.The two-tailed $p$ value equals 0.7415 . 
Table 4: Comparison of causes of failure and average time of surgery between groups $A$ and $B$

\begin{tabular}{|l|c|c|c|}
\hline \multicolumn{1}{|c|}{ Causes of failure } & Group A & Group B & p value \\
\hline Cicatricial closure of the ostium & 5 & 3 & $>.01$ \\
\hline Post-operative granuloma blocking ostium & 1 & - & $>.01$ \\
\hline Patent syringing but persistant watering due to ectropian & - & 1 & $>.01$ \\
\hline Failure to identify and dissect sac & - & 1 & $>.01$ \\
\hline Average surgical time (minutes) & $20.25 \pm 4.35$ & $31.35 \pm 5.75$ & $<0.001^{\dagger}$ \\
\hline
\end{tabular}

Independent $t$ test

Conventional DCR is a procedure which is highly successful with a reported success rate varying between $85 \%$ to $99 \%$ (Warren et al, 2005).The success of DCR depends on the proper size and location of a patent and mucosalined anastomosis between the lacrimal sac and the nose. Though Pandya VB et al (2010) showed no significant difference in outcome between patients in whom mucosal flaps were sutured to those who did not have either flap sutured at the time of surgery, our experience shows more failure rate of Flapless DCR (unpublished data). In these cases circumosteal MMC had not been instilled and ostium was not made with bone trephine. Conventional External DCR with its reported success rates of 90-95\% (Warren et al, 2005; Rabina Get al, 2013 ) is still considered to be the gold standard for PANLDO. However, the success rate at the end of one year in both groups A and B were comparable in our study $(p=-0.77)$. This can be attributed to ensuring an adequate size osteum with smooth margins by using Arrugas bone trephine (size 10) and intraoperative application of Mitomycin C in Group A patients. Use of circumosteal MMC may have inhibited scarring and granulation tissue proliferation at the osteotomy site and and also prevented adhesion between osteotomy site and nasal septum (Goswami BJ et al, 2002; Kopp ED, 2004; Liao LS et al, 2000). Mitomycin C (MMC), an antiproliferative agent significantly inhibits fibrosis and vascular ingrowth ([Goswami BJ et al, 2002; Kopp ED, 2004; Tsai CC, 2002). A study by Ali et al (2015) showed both topical and COS-MMC produce marked changes in nasal mucosa with more significant changes in COS-MMC group. These changes may also help in increasing the success of Flapless DCR when combined with circumosteal MMC by preventing cicatricial changes of the ostium. In a study of intraoperative MMC with DCR, Kao et al(1997) found that the ostium was significantly larger in the MMC group than the control group. Ugurbas et aI(1997) studied the histopathologic effects of MMC on transnasal DCR by soaking the osteotomy site in MMC $0.5 \mathrm{mg} / \mathrm{mL}$ for 2.5 minutes. The specimens were examined microscopically and were compared with control specimens. Microscopic 
examination found attenuated epithelium and looser, hypocellular subepithelial connective tissue in the MMC specimens. This finding substantiates the efficacy of MMC application with histopathologic evidence of the same.

Onerci etal (2000) noted that the most common causes of failure are inadequate lacrimal sac marsupialization, inadequate osteotomy, and improper localization of sac. leading to cicatricial closure of the osteum. Tearing of the nasal mucosa due to improper bone removal is another cause of failure (Burkat, 2018) in Ext DCR. Using the Arrugas bone trephine (size $10 \mathrm{~mm}$ ) as in group A, makes it easier to fashion an adequate osteotomy of $10 \mathrm{~mm}$ size with a smooth margin(Ali et al, 2014) which along with Circumosteal MMC prevents scarring with cicatricial closure of ostium. This technique has been used previously by us in failed DCR (Mohan et al, 2019). Since lacrimal sac marsupialization is not needed and only a collar of sac around the common internal opening is needed, loss of sac integrity does not affect the outcome. As no anastomosis has to be made, loss of nasal mucosa also does not affect the surgical modality either. This might explain the comparable success of the two procedures. Inexperienced surgeons and trainees may also have a better success rate with this technique. It can also be an alternative surgical technique when there is loss of the sac and nasal mucosa. However, more studies are needed to substantiate it.
The mean surgical time was assessed from skin incision to closure of the wound. It was found to be significantly lower in group A (mean $15 \pm$ $4.35 \mathrm{mins}$ ) than group B (mean $31.35 \pm 5.75 \mathrm{mins}$ ). Surgical time was saved by faster osteotomy creation by trephine and doing away with the need to create a mucosal flap and anastomosing with the lacrimal flap. The tedious nature and time taking procedure discourages even trained surgeons from doing DCR surgeries especially when the operative load of cataract is high. This technique being faster and equally effective as Ext DCR can encourage trained surgeons also to do more sac surgery.

\section{CONCLUSION}

Arrugas bone trephine-assisted Flapless DCR with COS-MMC is a viable alternative to conventional Ext DCR with comparable success rate, shorter surgical time, faster learning curve and ease of doing. In cases with loss of lacrimal flap or nasal mucosa conversion to this technique can be useful.

\section{Limitations}

More number of surgeries need to be done on larger sample size to validate this technique. Longer follow up needs to be done to know the consequences of subperiosteal injection of MMC.

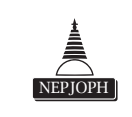




\section{REFERENCES}

Ali M, Wormald P, Psaltis A (2014). Dacryocystorhinostomy ostium: parameters to \& nbsp; evaluate and DCR ostium scoring. Clinical Ophthalmology:2491.

Ali M, Baig F, Lakshman M, Naik M (2015). Electron Microscopic Features of Nasal Mucosa Treated with Topical and Circumostial Injection of Mitomycin C. Ophthalmic Plastic \& Reconstructive Surgery, 31(2):103-7.

Burkat C, Lucarelli M (2006). Ophthalmology, 113(1):162-3.

Ezra E, Restori M, Mannor GE, Rose GE (1998). Ultrasonic assessment of rhinostomy size following external dacryocystorhinostomy. Br J Ophthalmol,82(7):786-9.

Goswami BJ, Chakravarthy D, Das K (2002). Mitomycin C as useful adjunct in external dacryocystorhinostomy in scar-prone condition. All India Ophthalmological Society Year Book:517-9.

Iqbal A, Khan O (2012) External dacryocystorhinostomy with and without intraoperative mitomycin-C application in adults. Ophthalmology;10(3):262-5.

Kamal S, Ali M, Naik M (2014). Circumostial Injection of Mitomycin C (COS-MMC) in External and Endoscopic Dacryocystorhinostomy. Ophthalmic Plastic \& Reconstructive Surgery, 30(2):187-90.

Kao, S., Liao, C., Tseng, J., Chen, M, Hou P(1997). Dacryocystorhinostomy with Intraoperative Mitomycin C. Ophthalmology, 104(1):86-91.

Kopp E (2004). Epiphora as a side effect of topical mitomycin C. British Journal of Ophthalmology, 88(11):1422-4.

Liao S (2000). Results of intraoperative mitomycin C application in dacryocystorhinostomy. British Journal of Ophthalmology, 84(8):903-6.

McLean C, Cree I, Rose G (1999). Rhinostomies: an open and shut case?. British Journal of Ophthalmology, 83(11):1300-1.

Mohan N, Bhaskar G, Sinha BP, Kumari A (2019). Flaplessmodified Toti's procedure with use of circumosteal Mitomycin C as an adjunctive therapy in management of failed Dacryocystorhinostomy (DCR). Journal of Medical Science And clinical Research, 7(7).

Onerci M, Orhan M, Ogretmenoğlu O, Irkeç M (2000). Long-term results and reasons for failure of intranasal endoscopic dacryocystorhinostomy. Acta Otolaryngol,120(2):319-22.

Pandya, V., Lee, S., Benger, R., Danks, J., Kourt, G., Martin, P., Lertsumitkul, S., McCluskey, P, Ghabrial R (2010). The Role of Mucosal Flaps in External Dacryocystorhinostomy. Orbit, 29(6):324-7.

Rabina G, Golan S, Neudorfer M, Leibovitch I (2013). External Dacryocystorhinostomy: Characteristics and Surgical Outcomes in Patients with and without Previous Dacryocystitis. Journal of Ophthalmology:1-4.

Tarbet KJ, Custer PL (1995). External dacryocystorhinostomy. Surgical success, patient satisfaction, and economic cost. Ophthalmology,102(7):1065-70.

Tsai C, Kau H, Kao S, Hsu W, Liu J (2002). Efficacy of probing the nasolacrimal duct with adjunctive Mitomycin-C for epiphora in adults. Ophthalmology, 109(1):172-4.

Toti A (1904). Nuovometodoconservatore di curaradicaledellesuporazionichroniche del saccolacrimale. Clin Mod Firenze, 10:385-9.

Ugurbas SH, Zilelioglu G, Sargon MF, Anadolu Y, Akiner M, Aktürk T (1997). Histopathologic effects of mitomycin-C on trans nasal dacryocystorhinostomy. Ophthalmic Surg, Lasers; 28:300-4.

Warren J, Seiff S, Kavanagh M (2005). Long-Term Results of External Dacryocystorhinostomy. Ophthalmic Surgery. Lasers and Imaging Retina,36(6):446-50. 